\title{
Heavy metal behaviour during RDF gasification
}

\author{
G. Compagnone, P. De Filippis, M. Scarsella, N. Verdone \\ \& M. Zeppieri \\ Università degli Studi di Roma, "La Sapienza", \\ Dipartimento di Ingegneria Chimica, dei Materiali, \\ delle Materie Prime e Metallurgia, Roma, Italy
}

\begin{abstract}
Solid wastes, and especially RDF in dealing with the growing presence of organic compounds, mainly plastics, can be considered an important source of energy owing to their inexpensiveness and large availability. However, the presence of heavy metals in the waste can result in a recycling problem when thermal treatment is involved. In fact, small amounts of these metal species can be found in the gaseous stream, and this is particularly true for gasification processes. This work investigates the possibility of using theoretical calculations to evaluate the amount of volatile metal species in the gas stream, obtained by a gasification process, in order to select the adequate gas cleaning facilities. To this aim, the chemistry and volatility of the heavy metals $\mathrm{As}, \mathrm{Cd}, \mathrm{Cr}, \mathrm{Cu}, \mathrm{Hg}, \mathrm{Mn}, \mathrm{Ni}$, $\mathrm{Pb}, \mathrm{Sb}, \mathrm{Sn}$ and $\mathrm{Zn}$, commonly present in $\mathrm{RDF}$, were investigated both theoretically and experimentally at different gasification conditions. A theoretical approach at equilibrium conditions based on thermodynamic data was performed by means of the total Gibbs free energy minimization method. The equilibrium distribution of the trace element species formed under reducing conditions in the 700-1300 K temperature range was calculated. The theoretical results are in substantial accordance with experimental data obtained using a bench scale gasification reactor. This study demonstrates that is possible to predict with reasonable conditions the operating conditions of a RDF gasifyier in order to obtain a syngas with a controlled content of polluting compounds. Keywords: gasification, RDF, trace metals, thermodynamic simulation.
\end{abstract}




\section{Introduction}

Solid wastes, in dealing with the growing presence of organic compounds, especially plastics, can be considered an important source of energy since they are inexpensive and easily obtainable materials $[1,2]$. However, many municipal waste streams contain heavy metal species that during the thermal treatment may change their physical and chemical form and in some amounts volatilize and be released to the atmosphere together with small particulate matter. The fate of heavy metals and the consequent environmental impact of their compounds is affected by several parameters such as: the operating conditions, the composition of the inlet feed, the physical characteristics of the metal and its compounds. In this contest, the study of the behaviour of the trace elements (e.g. $\mathrm{Pb}, \mathrm{Cd}, \mathrm{Sb}$ ) contained in waste as RDF has considerable importance [3]. In fact, even if these compounds are present in the wastes in very low concentration, they may cause various environmental or technological problems when released into the atmosphere [4]. Knowledge of the partition of the volatile and condensed heavy metals species during a thermal process is important in order to assess the related emission potential and to develop suitable systems for the reduction of volatile species [5-9]. The objective of this study is therefore to investigate the equilibrium distributions of the more relevant trace elements present in a typical urban waste during gasification processes and to compare simulation results with those obtained experimentally from a lab scale fixed bed gasifyer. The focus has been fixed on the gasification of refused derived fuel (RDF) that owing to its relatively constant composition and good transportation and storage characteristics constitutes a suitable feed in gasification processes for the production of fuels and/or energy [10].

\section{Thermodynamic model}

In order to investigate the fate of several trace elements in thermal conversion, the equilibrium composition of the resulting heterogeneous chemical system was calculated at different operating conditions according to a method based on the total Gibbs free energy minimisation [11-14]. The total Gibbs function was calculated assuming as reference state of the molecular species the gas state at the pressure of 1 bar and temperature of $298 \mathrm{~K}$, considering the syngas as an ideal gas mixture and assuming that each solid species forms a separate phase. Under these conditions, the expression of the Gibbs free energy of the system can be written as:

$$
n G=\sum_{i=1}^{N} n_{i} \Delta G_{f i}^{o}+\sum_{i=1}^{N} n_{i} R T \ln P+R T \sum_{i=1}^{N} n_{i} \ln \frac{n_{i}}{\sum_{i=1}^{N} n_{i}}+\sum_{j=1}^{M} n_{j} \Delta G_{f j}^{o}
$$

where $n G$ is the total Gibbs energy $(\mathrm{kJ}), n_{i}$ is the number of moles of the $i$-th component in gaseous phase, $n_{j}$ is the number of moles of the $j$-th component in separate solid phase, $N$ is the total number of the gaseous species, $M$ the total 
number of solid species and solid separate phases, $\Delta G_{f i}^{\circ}$ and $\Delta G_{f j}^{\circ}$ are the formation Gibbs free energies of the species $i$ and $j\left(\mathrm{kJmol}^{-1}\right)$, respectively, $R$ is the universal gas constant $\left(\mathrm{kJK}^{-1} \mathrm{~mol}^{-1}\right)$ and $T$ is the absolute temperature of the system $(\mathrm{K})$. The constrains introduced by the material balance of each element $k$ are expressed by the relations:

$$
\sum_{l=1}^{N+M} \sum_{k=1}^{K}\left(n_{l} a_{l k}-A_{k}\right)=0
$$

where $a_{l k}$ is the number of atom masses of the $k$-th element in the $l$-th chemical species at the equilibrium condition, $A_{k}$ is the total number of atom masses of the $k$-th element and $K$ is the number of atomic species.

To minimize equation (1) under the constrain (2), the method of Lagrange's undetermined multipliers was adopted [15]. The software developed in this work is based on the SOLGASMIX-PV code [16].

As a thermodynamic approach, the method used in this work does not take into account the kinetic aspects of the reactions, physical adsorption, chemisorption and capillary condensation phenomena. The gas was assumed ideal and all condensed phases were considered as pure. The presence of ash forming elements, i.e. $\mathrm{Al}, \mathrm{Ca}, \mathrm{Fe}, \mathrm{K}, \mathrm{Mg}, \mathrm{Na}$ and $\mathrm{Si}$, was not considered although these compounds could influence the distribution and the composition of the metal species. No mixing models, in order to describe non-ideal behaviour of the system, were used. In spite of the above mentioned limitations, the method of determining stable phases, assuming global equilibrium, is at present one reliable computational possibility for generating knowledge about the chemistry of heavy metals in combustion systems.

Table 1: $\quad$ Main physico-chemical characteristics of the RDF.

\begin{tabular}{|l|c|}
\hline Bulk density $\left(\mathrm{kg} \mathrm{m}^{-3}\right)$ & $380 \pm 10$ \\
\hline Humidity (mass \%) & $8.1 \pm 0.3$ \\
\hline Ashes (mass \% dry basis) & $16.3 \pm 0.5$ \\
\hline Lower heating value $\left(\mathrm{MJ} \mathrm{kg}^{-1}\right)$ & $17.8 \pm 0.3$ \\
\hline Element (mass \%) & \\
\hline Carbon & $55.1 \pm 0.3$ \\
\hline Hydrogen & $11.5 \pm 0.2$ \\
\hline Oxygen & $13.7 \pm 0.7$ \\
\hline Nitrogen & $3.1 \pm 0.2$ \\
\hline Sulfur & $0.04 \pm 0.01$ \\
\hline
\end{tabular}




\section{Experimental}

\subsection{Materials}

The RDF used in this work was supplied by a local waste treatment company. Because its heterogeneity, the RDF was grounded to a grain size less than $1 \mathrm{~mm}$ before its characterization and use. The main physico-chemical characteristics and the chemical analysis of the processed RDF are reported in Tables 1 and 2, respectively.

Table 2: $\quad$ RDF trace elements content.

\begin{tabular}{|c|c|}
\hline Element & $\left(\mathrm{mg} \mathrm{kg}^{-1}\right)$ \\
\hline $\mathrm{Cl}$ & 1007 \\
\hline $\mathrm{F}$ & 9.59 \\
\hline $\mathrm{Br}$ & 94.97 \\
\hline $\mathrm{As}$ & 0.7 \\
\hline $\mathrm{Cd}$ & 0.8 \\
\hline $\mathrm{Cr}$ & 76 \\
\hline $\mathrm{Cu}$ & 320 \\
\hline $\mathrm{Mn}$ & 66 \\
\hline $\mathrm{Hg}$ & 0.5 \\
\hline $\mathrm{Ni}$ & 166 \\
\hline $\mathrm{Pb}$ & 880 \\
\hline $\mathrm{Sn}$ & 1.1 \\
\hline $\mathrm{Sb}$ & 81 \\
\hline $\mathrm{Zn}$ & 445 \\
\hline
\end{tabular}

\subsection{Experimental equipment and procedures}

The experimental apparatus used in this work is composed of two main sections: reaction and product collection. The reaction section is a classical updraft gasifyer reactor. The reactor consists of a $45 \mathrm{~mm}$ i.d., $550 \mathrm{~mm}$ length stainless steel tube equipped with a grid on the bottom side. The collection system consists of a high temperature filter stage (necessary to remove the particulates) followed by a water-cooled exchanger (for separating water and condensable fractions) and by a final gas filter.

The RDF feed was introduced in the reactor through a piston system at regular intervals of time in order to assure the continuity of the process. Because 
its low bulk density and cohesive characteristics, and in order to reduce the dragging phenomena in the reactor, the RDF powder was pelletized before its use as feed. The pellets of cylindrical shape (about $10 \mathrm{~mm}$ diameter and $6 \mathrm{~mm}$ height, with a mass of approximately $0.4 \mathrm{~g}$ ) were produced by compression. An oxygen-steam mixture was introduced through the bottom of the reactor.

The selected operating conditions were: $700 \pm 20^{\circ} \mathrm{C}$ for the gasification reaction; oxygen/carbon ratio equal to $0.2 \mathrm{~mol} / \mathrm{mol}$ and a steam/charge ratio of about $0.5 \mathrm{~g} / \mathrm{g}$ in order to control the reaction temperature. The runs were performed at a constant feed-rate and at atmospheric pressure. The duration of each test was two hours; the amount of sample feed in each run was about $800 \mathrm{~g}$.

The off-gas, mainly constituted by hydrogen, carbon monoxide, carbon dioxide, gaseous hydrocarbons, volatile and non-volatile substances, steam and char, was sent to the collection system. The condensed fractions together with slag and fly ashes recovered on the final filter were analyzed for metal content.

Before starting each test, the equipment was preheated to the desired temperature. To assure safe working conditions, the feed was introduced before starting the oxygen-steam injection. This way, the charge undergoes immediate pyrolysis, producing char that in turn falls on the bottom of the reactor and reacts with the oxygen-steam introduced through the grid. This procedure avoids the formation of explosive mixtures in the gas phase.

\section{Results and discussion}

To compare the experimental and simulation results, the waste composition considered as the basis for the equilibrium calculations was that reported in table 1, while the oxygen/carbon and the oxygen/steam ratios were those fixed for the experimental test. The parameter of the simulation was the temperature, ranging from 700 to $1200 \mathrm{~K}$. The equilibrium calculations were performed considering 11 trace elements: As, Cd, Cr, Cu, Hg, Mn, Ni, Pb, Sb, Sn, Zn, whose content in the RDF is reported in Table 2.

The behaviour of the different trace metals can be classified on the basis of the calculated equilibrium composition profiles in the temperature range considered in this study: those that can exist only in condensed phases, those that can exist only in gas phase and those that are distributed between the phases.

$\mathrm{Cr}, \mathrm{Cu}$ and $\mathrm{Ni}$ are the trace metals in the first group, because in the considered temperature range they can exist only as condensed species, respectively $\mathrm{Cr}_{2} \mathrm{O}_{3}(\mathrm{cr}), \mathrm{Cu}(\mathrm{cr}, \mathrm{l})$ and $\mathrm{Ni}(\mathrm{cr})$.

The second group includes $\mathrm{As}, \mathrm{Cd}, \mathrm{Hg}, \mathrm{Sb}$ and $\mathrm{Sn}$, that in the considered temperature range exist only as gaseous species. For arsenic the dominant compound between 700 and $840 \mathrm{~K}$ is $\mathrm{As}_{4}(\mathrm{~g})$ while above $840 \mathrm{~K}$ the stable form is $\mathrm{AsO}(\mathrm{g})$. Several other gaseous species exist in all the temperature range, but in negligible amounts. For tin, in the temperature interval between 700 and $965 \mathrm{~K}$ $\mathrm{SnCl}_{2}(\mathrm{~g})$ is the most stable compound, while $\mathrm{SnS}(\mathrm{g})$ is the major species formed above $965 \mathrm{~K}$. Other gaseous species exist, also for tin, in all the temperature range, but their amount is negligible if compared with the two main species. For mercury the only stable species in the examined temperature interval is $\mathrm{Hg}(\mathrm{g})$, 
while for antimony the dominant compounds is $\mathrm{SbS}(\mathrm{g})$ up to $1100 \mathrm{~K}$ and $\mathrm{SbO}(\mathrm{g})$ at higher temperatures.

$\mathrm{Mn}, \mathrm{Pb}$ and $\mathrm{Zn}$ belong to the last group where both gas and condensed phases coexist. For manganese, $\mathrm{MnS}(\mathrm{cr}, \mathrm{l})$ for temperatures below $1100 \mathrm{~K}$ and also $\mathrm{MnO}(\mathrm{cr})$ for temperatures above $800 \mathrm{~K}$ coexist with minor amounts of $\mathrm{MnCl}_{2}(\mathrm{~g})$. For $\mathrm{Pb}$ and $\mathrm{Zn}$ the equilibrium composition profiles for the related species are reported in Figure 1 and 2 respectively, where the details relative to minor species are also reported in an enlarged scale.
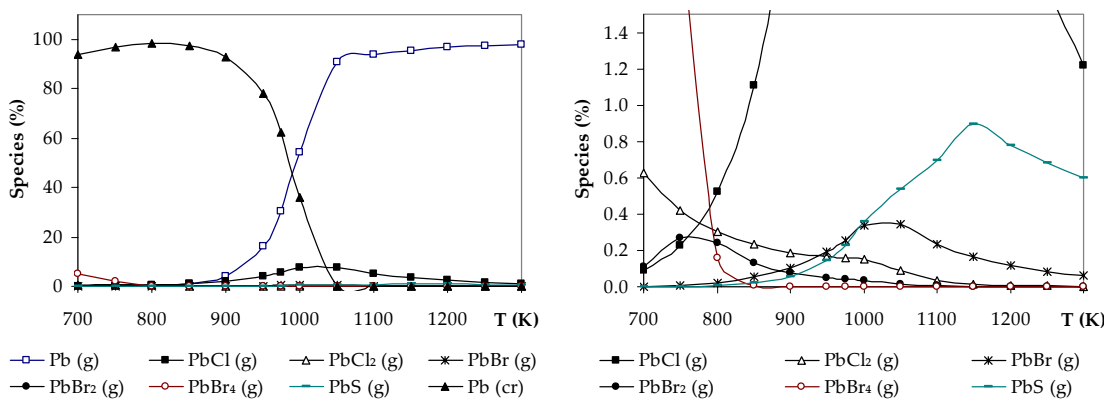

Figure 1: Equilibrium composition profiles for $\mathrm{Pb}$.
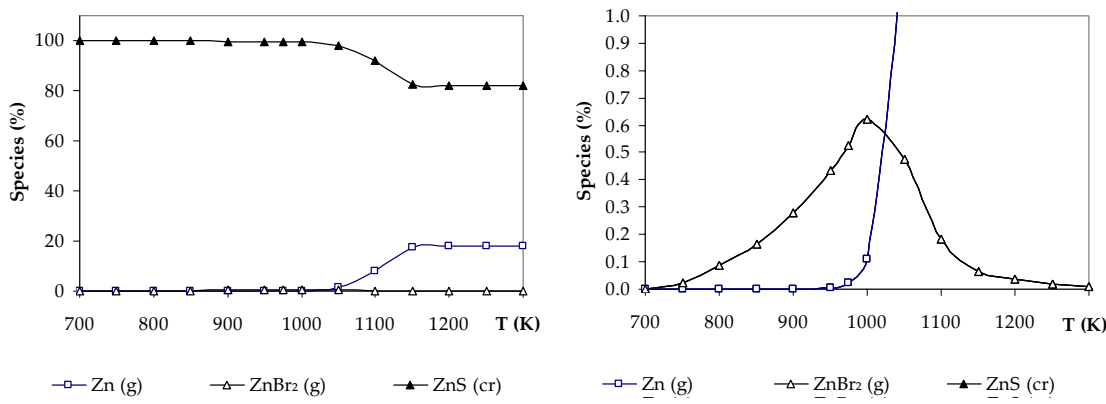

Figure 2: $\quad$ Equilibrium composition profiles for $\mathrm{Zn}$.

To validate the obtained equilibrium data, the attention has been focused on the behaviour of $\mathrm{Cr}, \mathrm{Cu}, \mathrm{Mn}, \mathrm{Ni}, \mathrm{Pb}, \mathrm{Sb}$ and $\mathrm{Zn}$, because only for these metals significant amounts in the RDF used for experimental gasification tests were found. At the end of each test a mass balance for each metal was carried out. Only those results showing a discrepancy in the metal balance less than $10 \%$ were retained.

A comparison between the experimental and calculated amounts of the species formed by the selected elements in both the condensed and gaseous phases is shown in Table 3, where the calculated data are reported for the two extremes of the experimental temperature range $\left(680\right.$ and $\left.720^{\circ} \mathrm{C}\right)$. 
Table 3: $\quad$ Comparison between experimental and calculated data.

\begin{tabular}{|c|c|c|c|c|}
\hline & \multicolumn{2}{|c|}{ Condensed phase (\%) } & \multicolumn{2}{c|}{ Gas phase (\%) } \\
\hline & Experimental & Calculated & Experimental & Calculated \\
\hline $\mathrm{Cr}$ & $99 \pm 1$ & 100.0 & $1 \pm 1$ & 0.0 \\
\hline $\mathrm{Cu}$ & $71 \pm 5$ & 100.0 & $28 \pm 3$ & 0.0 \\
\hline $\mathrm{Mn}$ & $99 \pm 1$ & $99.6 \div 98.3$ & $1 \pm 1$ & $0.4 \div 1.7$ \\
\hline $\mathrm{Ni}$ & $76 \pm 6$ & 100.0 & $23 \pm 3$ & 0.0 \\
\hline $\mathrm{Pb}$ & $63 \pm 2$ & $78.2 \div 36.1$ & $36 \pm 1$ & $21.8 \div 63.9$ \\
\hline $\mathrm{Sb}$ & $11 \pm 2$ & 0.0 & $88 \pm 3$ & 100.0 \\
\hline $\mathrm{Zn}$ & $97 \pm 2$ & $99.6 \div 99.4$ & $2 \pm 1$ & $0.4 \div 0.6$ \\
\hline
\end{tabular}

A good agreement of the experimental results with the predicted ones can be observed for $\mathrm{Cr}, \mathrm{Mn}, \mathrm{Pb}$ and $\mathrm{Zn}$, while for $\mathrm{Cu}, \mathrm{Ni}$ and $\mathrm{Sb}$ the measured partition does not agree with that calculated at the equilibrium condition. Antimony is the only trace metal showing measured content in the condensed phase greater than the calculated one. This result could indicate that for $\mathrm{Sb}$ species the thermodynamic equilibrium is not reached.

The thermodynamic analysis performed in a limited temperature range could be responsible of the bigger amount of nickel and copper experimentally found in the gas phase. In fact, the thermodynamic model was applied just in the reaction zone, i.e. in the temperature range $680-720^{\circ} \mathrm{C}$. Then the observed behaviour could be explained considering that volatile carbonyl complexes should be formed at the lower temperatures of the upper reactor section, where drying and pyrolysis of the feed in reduced atmosphere happen. Due to the reactor countercurrent geometry the volatile species of these metals, if formed, could be directly fluxed by the off-gas, so they are prevented from reaching the high temperature reaction zone where decomposition happens. Finally, also the possibility that a fraction of these elements can be entrained by the off-gas as a small particulate matter should be considered.

\section{Conclusions}

The developed thermodynamic model based on the free Gibbs energy minimization has proved to be a useful tool to qualitatively and quantitatively predict the amount of metallic compounds in the gas stream from a waste gasifyier. This approach has shown a limitation with respect to some of the considered trace metals, namely $\mathrm{Sb}, \mathrm{Ni}$ and $\mathrm{Cu}$. However, such a limitation can be attributed to the reactor geometry, rather that to the validity of the used approach. An explanation of the deviation of the predicted partitions from the measured ones is presented. This study demonstrates that the thermodynamic 
approach can confidently estimate the influence of different gasification operating conditions on the fate of volatile metallic compounds. The good general agreement between simulations results and experimental measures shows that the predictive procedure based on the characterization of the thermodynamic favourite species is a reliable method for an environmentally sound conduction of waste gasification processes.

\section{References}

[1] Borgianni C., De Filippis P., Pochetti F., Paolucci M., Gasification process of wastes containing PVC. Fuel, 81, pp. 1827-1833, 2002.

[2] Belgiorno V., De Feo G., Della Rocca C., R. M. A. Napoli, Energy from gasification of solid wastes. Waste Management, 23, pp. 1-15, 2003.

[3] Chen J. C., Wey M. Y., Su J.L., Two stage simulation of the major heavymetal species under various incineration conditions. Environment International, 24(4), pp. 451-466, 1998.

[4] Linak W. P., Wendt J. O. L., Toxic metal emission from incineration: mechanism and control. Prog. Energy Combust. Sci., 19, pp. 145-185, 1993.

[5] Frandsen F., Johansen K. D., Rasmussen P., Trace elements from combustion and gasification of coal. An equilibrium approach. Prog. Energy Combust. Sci., 20, pp. 115-138, 1994.

[6] Somoano M. D., Martinez Tarazona M. R., Trace element evaporation during coal gasification based on a thermodynamic equilibrium calculation approach. Fuel, 82, pp. 137-145, 2003.

[7] Sorum L., Frandsen F. J., Hustad J. E., On the fate of heavy metals in municipal solid waste combustion. Part I: devolatilisation of the heavy metals on the grate. Fuel, 82, pp. 2273-2283, 2003.

[8] Sorum L., Frandsen F. J., Hustad J. E., On the fate of heavy metals in municipal solid waste combustion. Part II: from furnace to filter. Fuel, 83, pp. 1703-1710, 2004.

[9] Borgianni C., De Filippis P., Pochetti F., Paolucci M., Prediction of syngas quality for two-stage gasification of selected waste feedstocks. Waste Management, 24, pp. 633-639, 2004.

[10] Cozzani V., Nicolella C., Petarca L., Rovatti M., Tognotti L., A fundamental study on conventional pyrolysis of a refuse-derived fuel. Ind. Eng. Chem. Res., 34, pp. 2006-2020, 1995.

[11] Trouvé G., Kauffmann A., Delfosse L., Comparative thermodynamic and experimental study of some heavy metal behaviors during automotive shedder residues incineration. Waste Management, 18, pp. 301-307, 1998.

[12] Verdone N., De Filippis P., Thermodynamic behaviour of sodium and calcium based sorbents in the emission control of waste incinerators. Chemosphere, 54, pp. 975-985, 2004.

[13] Barin I., Knacke O., Thermochemical Data of Pure Substances, VCH Verlagsgesellschaft: Weinheim, 1989. 
[14] Chase M. W. (ed), Nist-JANAF Thermochemical Tables, 4th Ed. American Institute of Physics: Woodbury, New York, 1998.

[15] Perry, R.H., Green, D. W. (eds), Perry’s Chemical Engineers' Handbook, 6th Ed. McGraw-Hill: Singapore, 1984.

[16] Besmann, T.M., SOLGASMIX-PV, a computer program to calculate equilibrium relationships in complex chemical systems. ORNL/TM-5775, Union carbide Corp., Nucl. Div., Oak Ridge Natl. Lab., 1977 